\title{
The relationship between sport's endorsement in social media and consumers' attitude towards the advertising
}

\author{
Shohreh Sadeghi * \\ Tehran University, Tehran, Iran
}

\section{Keywords \\ Celebrity athletes \\ Endorsement \\ Sport marketing \\ Consumer attitude}

Received: 9 September 2019

Accepted: 11 November 2019

Published: 12 February 2020

\begin{abstract}
This study aimed to investigate the attitude towards advertising promoted by sports' endorsement in social media. The present study was correlation research. The statistical population was Iranian university students. A total of 236 questionnaires were collected using cluster-random sampling. In inferential statistics, Pearson correlation coefficient and multiple regression were used for data analysis. To assess the reliability of the questionnaire, Cronbach's Alpha was used (0.94\%). The coefficient of determination $\left(R^{2}\right)$ shows the variance explanation and the changing dependent variable by the sum of independent variables and the factors related to sports endorsers explaining $20 \%$ of consumers' attitudes towards advertising. $F=15.02$ indicates that four independent variables have high explanatory power and well- explained the extent of the variation of the dependent variable. In general, the results of this study showed that there is a significant relationship between dependent and independent variables, and among these four factors, the endorsed testimonial can be a good predictor of the consumer attitude towards the advertisements promoted by athletes. This analysis, one can hope that the sport's celebrities and their popularity will be used to improve the position of advertising on social media and society and will seek to inform

and identify the product to customers, as well as easier access, with trust the quality and services of the products.
\end{abstract}

(C) 2020 The Author(s). Published by TAF Publishing.

\section{INTRODUCTION}

The ability of advertisements to originate a supportive attitude towards a brand or product greatly depends on the consumers' attitude towards the advertisement (Darmawan, Mardikaningsih, \& Hariani, 2019). Promoting a product by a celebrity is a great way to encourage audiences to buy the product. The Strategy; i.e. this product is tried and true, usually has good results, because this strategy is based on the relative approach; if you like a famous person, you normally trust him/her and act on away that recommended and advertised by him or her. Celebrity endorser has a significant positive effect on the consumers' purchase decision (Pranee \& Papapankaid, 2017; Putra \& Ningrum, 2019). Nowadays, with the increasing popularity of sports and the success of well-known athletes, the use of athletes in promoting and marketing to products has become a very significant phenomenon (Jatto, 2014). In the meantime, many companies compete in the use of celebrity athletes in their advertising to promote their products, and they are struggling to gain more profit by understanding this emerging approach and promoting their products by athletes (Cunningham, 2012). In 2010, sponsors invested a total of $\$ 46.3$ billion on their advertising campaigns, which endorsed by sport's endorsers. Only in the US $\$ 17.2$ billion were spent (Koo, Ruihley, \& Dittmore, 2012). Traders in the United States and other countries have recognized that sports endorsement as the most valuable investment brings them to the multidisciplinary performance of their industry. The benefits of this investment include: increased and return of capital, a willingness and a positive attitude towards the products and the services, the creation of appealing for products, being better at obtaining, keeping and retaining customers and the possibility of increasing product sales, promotions and at the end increasing brand loyalty (Saputra \& Dewi, 2016; Schaefer, Parker, \& Kent, 2010). Perhaps this is hard to believe, but the result of widespread

*corresponding author: Shohreh Sadeghi

${ }^{\dagger}$ email: shohreh.sadeghi@ut.ac.ir 
use of sports endorsement has a stronger memorization in people's minds and save images of athlete endorsers more than other people. For example, people prefer to see images or videos from someone like Michael Jordan than a picture of Bill Clinton or pictures of politicians, economists or historian figure (Andrews \& Durvasula, 1991; Manta, 2013; Mudrick, Sauder, \& Davies, 2019). It is also worthy to mention, companies that align themselves with sport must accept the unpredictable risks that are common in sport, such as the performance of an athlete, athlete character and the player's position, all affects the value of sport as a promoting tool (Cunningham \& Bright, 2012). Today, for many people, it is hard to imagine a society without sports and athletes as a key factor in their life. Sports news has its section in most newspapers, and they can be viewed on various TV channels and used as a focal point for the gathering of many communities (Manta, 2013).

Among the advertising tools, mass media have had more success in influencing their users (Williamson, 2011). The fans follow their favorite celebrities through the mass media, without waiting for the next publication of journals or even morning newspapers (Cunningham \& Bright, 2012). Mass media is an important tool for promoting and advertising companies. They act as a two-way lines for their fans to get new information (Campbell, Pitt, Parent, \& Berthon, 2011; Cunningham, 2012). Social media has become widely accepted as an important tool of advertising since its inception amongst various categories of users around the world, especially admitted by adults, young people, and adolescents who migrated from traditional Media (Stever \& Lawson, 2013). Therefore, brands must have a social media presence. Advertising through social media is also more cost-effective and efficient than utilizing traditional media channels (Matenga, 2019). In this way, celebrities use social media as a concept that creates a two-way communication and interaction with their brand (Stever \& Lawson, 2013). The reasons for the popularity of social media are; because of easy communication, especially with the younger generation and the appropriate expense to promote products and brands (Smith \& Stewart, 2014; Sudarmiatin, 2019). The media also provided a way for celebrities to promote different products to their fans (Whiting \& Williams, 2013). Annually Millions of dollars are spent on celebrities by marketers (Elberse \& Verleun, 2012). These marketers have accepted the media as a communication concept that has a positive impact on consumers (Campbell et al., 2011). Therefore, it is necessary to ensure that these endorsing are effective and provide cost-benefit returns. Researches have shown that $88 \%$ of marketers are associated with social me- dia in their marketing strategies. Marketers and advertisers spend almost $\$ 60$ billion a year on marketing by social media (Whiting \& Williams, 2013). One of the reasons why social media overtaking other marketing tools is providing direct access between celebrities and their fans. These tools provide a place where celebrities can communicate directly with fans, as their fans prefer, want and are interesting to them (Stever \& Lawson, 2013). Social media has built a twoway communication channel between celebrities and public figures so that fans can better evaluate the real fact of their favorite celebrities (Cunningham \& Bright, 2012). Whiting and Williams (2013) sought to know; why people used social media? They concluded that the main reason for using social media was two-way action, information seeking, time-consuming, entertainment, relaxation. They explained the tendency of celebrities to communicate with their fans around the world has led them to select social media as the best communication tool to reach their goal. Fans also wanted to be a unique section of the world of popular people. People also use mass media as an alternative tool to have face-to-face communication with celebrities. It's easier for a fan to follow a well- known character through social media than in the real world (Whiting \& Williams, 2013). Therefore, with the growing popularity of sporting events, it seems that marketers and advertising companies have been spending millions of dollars on sports endorsement to improve their convincing and effective communications with customers. As companies continue to invest in sports endorsement, they also use social media for their online advertising and invest more in these platforms. They have accepted the tactics of using social media as part of their business and marketing strategy (Williamson, 2011). Therefore, social media play a role as a potential shortcut, where fans, athletes, and companies can appear in a common place for exchange and meeting each other (Cunningham \& Bright, 2012; Polat, Subay, \& Uluturk, 2018). Then it is common in sports for organizations to share stories with their fans (Laurell \& Söderman, 2018). By carefully survey on the marketing science, the effect of the presence of celebrities on the brand image and the behavior of consumers is easily recognizable. In some countries like India, the use of this type of advertising has led people to have a great deal of interest in using domestic products. In general, the success and performance of celebrities will have a huge impact on brand success. According to statistics since 1995, the use of celebrities in advertising has more than doubled. With the expansion of mass media, a new type of celebrity has emerged as a virtual celebrity (Mullin, Hardy, \& Sutton, 2014). In Iran since 1979 
(after the Islamic Revolution of Iran), the use of images or names of famous and well-known people in advertisements whose purpose was to raise awareness of consumers about products and services was banned. So in the eighties, the presence of athletes and artists was prohibited in advertising. In the late 1990s, Karim Bagheri broke this taboo after the Iranian national football team had qualified for the 1998 World Cup in France. He contracted with Darougar Holding (a factory make health and beauty products), for advertising, which faced strange criticism. In the 2000s, other famous athletes have also been used in advertising. And then the presences of other celebrity athletes in the advertisement and promotion of Iranian and non-Iranian products. In the meantime, Hossein Rezazadeh, who has two- time Olympic weightlift champion, broke the record of endorsing and advertising in Iran! Watta Mineral, Traktorsazi (Trucking factory), Behran Oils, and the most interesting and controversial endorsing was Robinson's real state in Dubai. Endorsing that has been the subject of criticism for a long time (Kahle \& Kahle, 2006). Recent studies have suggested that there is a chronological element to communications on social network sites (Leng \& Chiu, 2019), and with these interpretations, it seems that the space for the presences of celebrities in Iranian social media commercials have become a bit more acceptable and popular, but how this process will continue in the future is considerable. Due to the emergence of marketing in social media by us of sports' endorsement and a few researches have done in Iran, this study sought to examine whether the consumers' attitude towards advertising is influenced by athlete endorsement in social media?

\section{Hypothesis}

The hypothesis in this study consists of five hypotheses, namely:

H1: The relevance of the promotional message with endorsed product has a significant effect on attitude towards Ad.

H2: The involvement of the promotional message with product has a significant effect on attitude towards Ad.

H3: The testimonial or recommendation to product by athlete endorser has a significant effect on attitude towards Ad.

H4: The congruency between the product and athlete endorser has a significant effect on attitude towards Ad.

H5: There is a significant correlation between the sports' endorsers and consumers' attitude toward Ad.

\section{RESEARCH METHODOLOGY}

The present research is applied in terms of objective and descriptive-survey, correlational type, in terms of data collection. The statistical population of the study was university students all around Iran who were selected by cluster sampling. In this research, the relationship between sports' endorsement and attitude towards advertising in social media is examined. Using the Pearson correlation coefficient (with the confirmation of the assumptions of the use of parametric statistics). Multi-linear regression using to examine one dependent variable and more than one independent variables, the linear relation equation was determined between these variables. To assess consumers attitude toward advertising which endorsed by sports' celebrity a researcher made questioner which is operationalized from previous researches and the scale is revised according to the needs of this study, with a total of 40 questions. The items of questioner that used in this study were operationalized from previous researches which refers to the scale of the study of, (Cunningham \& Bright, 2012). The scale used by (Ohanian, 1990), was adapted for attitude towards advertising (14-questions). Sports' endorsement attributes consist of 4 sub-scale, including: 1- (Andrews \& Durvasula, 1991), was used for the relevance variable (4- questions). 2- Involvement variable (4-questions) adopted from (Swinyard, 1993). 3- (Feick \& Higie, 1992), was used for examining testimonial variable (5-questions). Athletes- product congruence variable (13- questions) was adopted from (Till \& Busler, 2000). The survey instrument utilized a fivepoint Likert scale anchored along strongly disagree (1) to strongly agree (5). Of the 289 questionnaires were distributed, 267 were returned, while 31 were discarded because they either were spoilt or had missing values, leaving only 236 usable surveys for subsequent statistical analysis. The reliability assessment for the instrument was ascertained by computing the Cronbach's alpha coefficient values (0.94). Regression analysis was conducted to ascertain the predictive validity of the study. Also, to ensure the validity of the questions and the items evaluated by the concepts, which is used in this research, the approval of 9 experts in the field of marketing and sport marketing who act in academic levels were used.

\section{RESULTS AND DISCUSSION}

In this section, the 1-5 hypotheses of this study are answered and discussion about it. Cronbach's $\alpha$ coefficient is used to measure the internal consistency between variables. The higher $\alpha$ coefficient indicates that the results of each item in the questionnaire tend to be more consistent, 
indicating that the questionnaire has higher reliability. As can be seen from Table 1 above, $\alpha$ values of the variables are all greater than 0.7 . Therefore, the questionnaire has good reliability values. Reliability and descriptive analysis are shown in Table 1.

TABLE 1. Reliability and descriptive analysis

\begin{tabular}{llll}
\hline \hline Variable & Mean & Std. Deviation & Cronbach's Alpha \\
\hline Attitude & 38.39 & 8.86 & 0.84 \\
Relevance & 11.99 & 3.24 & 0.70 \\
Involvement & 10.75 & 3.39 & 0.78 \\
Testimonial & 14.10 & 4.39 & 0.83 \\
Congruence & 37.26 & 11.00 & 0.91 \\
Total & 112.51 & 25.44 & 0.94 \\
\hline \hline
\end{tabular}

Findings in this study showed that from the four independent variables which tested, between three variables have a direct relationship with low intensity with depended variable. The relevance of the message with the advertised product (31\%), the involvement of the advertising message with product that endorsed (32\%), as well as the athleteproduct congruence (between the product advertised with the athlete endorser) (30\%). In other words, the positive attitude of people towards advertising which endorsed by athletes in social media is increasing with these three factors, but with a low intensity. The fourth factor was the testimonial, a recommendation and guarantee of messages that athletes send to advertise the products, had a direct and moderate relationship (44\%). This showed that recommendation and ensuring about products giving by sports' endorsement as a testimonial have a stronger impact on the attitudes toward advertising on social media.

TABLE 2. Results of the correlation matrix

\begin{tabular}{llllll}
\hline \hline Variable & Attitude & Relevance & Involvement & Testimonial & Congruency \\
\hline Attitude & 1 & 0.313 & 0.328 & 0.449 & 0.308 \\
relevance & & 1 & 0.572 & 0.599 & 0.599 \\
involvement & & & 1 & 0.623 & 0.642 \\
testimonial & & & & 1 & 0.617 \\
congruency & & & & & 1 \\
\hline \hline
\end{tabular}

Regarding the relationship between independent variables, the results of the correlation matrix according to Table 2, is shown that the relevance of the message with endorsed product, which provided by the athletes, was the highest correlation with the testimonial messages, as well as the congruency between product and the athlete endorser to the same extent as with 59.9\% which had a direct and strong relationship. The involvement of the promotional message also had the highest correlation with the congruency between the product and the athlete, which had a direct and strong correlation with $64 \%$. The next factor is the testimonial of the message provided by the athlete, which had the highest correlation with involvement variable by selecting an appropriate message with intensity of $62 \%$ and a direct relationship. Overall the attitude to advertising had the highest correlation with testimonial with $44 \%$.

TABLE 3. Regression analysis

\begin{tabular}{llllll}
\hline \hline $\boldsymbol{R}$ & $\boldsymbol{R}$ Square & Adjusted $\boldsymbol{R}$ square & Std. Error of the Estimate & $\boldsymbol{F}$ & Sig \\
\hline 0.454 & 0.206 & 0.193 & 5.28 & 15.02 & 0.00 \\
\hline \hline
\end{tabular}

To explore the relationship between the four dimensions of sports' endorsement and attitude towards advertisement a multiple regression is conducted. The results of the analysis are displayed in Table 3. The correlation coefficient $(R)$ between the variables is $(0.452)$ which indicates the corre- lation between the independent and dependent variables of the research. The number is more close to 1 , the correlation is stronger. According to the number obtained, the relation between the dependent and independents variables is accepted. $\left(R^{2}\right)$ value explains the overall relationship be- 
tween the dependent variable (attitude towards advertising) and the independent variables consisting of the four dimensions of sports' endorsement. The $(F)$ value shows the distance from the null hypothesis and the $(p)$ value explains the significance of the result. The result shows that the model is significant $(p<0.01)$ and differs from the null hypothesis. In other words, the relationship between the dependent and independent variables is accepted. $R^{2}$ value explains that $20 \%$ of the adjusted variance in attitude towards the advertising can be explained through the four dimensions of sports' endorsement. The adjusted $R$ square is used for the community. In this model, $19.3 \%$ of independent variables explain the attitude of people towards advertising, and $80.7 \%$ are affected by variables outside of our model. According to the number obtained for $F$, which is 15.02 , it is concluded that the regression model of research is a suitable model for this research, which explained four independent variables have high explanatory power and well-explain the extent of dependent variable variations. As a result, the regression model of research is accepted.

Regression analysis was also conducted on each branch of the proposed model against the dependent variable. Table 4 displays the unstandardized regression coefficients (B), and standardized regression coefficients $(\beta)$ for each variable. Regression analysis revealed that the model significantly ( $t$ $=8.290, p<0.01$ ), predicted attitude towards advertising which endorsed by athletes. In terms of individual relationships between the independent variables and attitude towards advertising, one out of four dimensions is supported through the regression, where testimonial $(t=4.506, p<$ $0.05)$, significantly predict attitude towards advertising. On the other hand, relevance ( $t=0.600, p>.05$ ), involvement ( $t$ $=0.724, p>.05)$, and congruence $(t=0.079, p>.05)$ are not supported by the model, $p$ values of 3 variables indicating their insignificance in contributing to explaining the relationship.

TABLE 4. The results of the unstandardized regression coefficients (B), and

\begin{tabular}{lllll}
\multicolumn{6}{c}{ standardized regression coefficients $(\beta)$} & & \\
\hline \hline & Unstandardized Coefficients & Standardized Coefficients \\
Beta & & $\boldsymbol{t}$ & Sig \\
\hline B & 12.01 & 0.048 & 8.290 & 0.00 \\
Renstant & 0.093 & 0.061 & 0.600 & 0.540 \\
Involvance & 0.130 & 0.378 & 0.725 & 0.469 \\
Testimonial & 0.590 & 0.007 & 4.506 & 0.00 \\
Congruence & 0.003 & 0.079 & 0.937 \\
\hline \hline
\end{tabular}

Constant (12/01), shows the extent of the dependent variable without the intervention of independent variables. On the other hands, the total effect of the four independent variables on the attitude toward advertising was $49.4 \%$ (total Beta column) and $50.6 \%$ were related to external factors. It is within our scope of research.

\section{CONCLUSION AND IMPLICATIONS}

In this study, some effective variables in advertising that were endorsed by athletes in social media and the consumers' attitude towards these advertising were examined. Advertising is a message that informed customers about a product, service or company through a monetary media and encourages them to buy the product. Advertising is a control device. A message that is passed on to the customer is selected and controlled, so it's content of information that a company likes to reach out to its customers. Because of this control, perhaps the credibility of these advertisements are decreased by customers (Mullin et al., 2014). As outlined in the results, there are four independent variables: the relevance of the promotional message with the product, the selection of appropriate messages or involvement, and the testimonial made by the athlete, as well as the congruency between the advertised product and the athlete. The attitude towards advertising was also considered as a dependent variable in this research, which examined each of these variables. In connection with the message, it is important to pay attention to two issues; one that, the relevant of the message with the product, it means, if the quality of a special running shoes is promoted, then the message type should refer directly to comfort, convenience, desirability and quality of shoes, and also choosing the right message (involvement) that emphasizes the specificity and uniqueness of the promotional item while running, not the beauty, color and variety of shoes. Findings showed, both of which have a direct, positive but low intensity with attitude toward advertising on social media as a dependent variable. The phenomenon of products advertising seems to find its place in the Iranian family, in particular, by using a famous athlete, an issue that encourages marketers to use these sports endorsers to promote their product to consumers. Previous studies reviled that, if the audience 
or consumers see a good relevance and involvement between the message, product, and endorser, this advertise can serve as a convincing and effective message on the perception of the audiences (Martin, 1996; Manta, 2013; Mullin et al., 2014). Choosing the right message as well as the product will have a proper impact on the viewer's perspective or perception (Manta, 2013). The relevance and involvement between message and product in advertising are important to consumers' attitude. Consumers consider advertising messages in various aspects. A good massage can be a good means for consumer assessment. There is a positive and significant relationship between the previous perception and the new consumer understanding of the product, after seeing or hearing the appropriate promotional message and their intention to purchase the product(Chiu, Wen, \& Lin, 2019; Martin, 1996).

Sometimes the perceptual distortion and insight of advertising occurs when the recipient of the message transmits the intention and purpose of the sender differently from the real meaning. This goes back to the carelessness in selecting a promotional message. This phenomenon can cause the message to be misunderstood and prevent marketers from achieving their advertising goals (Mullin et al., 2014). Ensuring a purposeful, clear, and specific message will make the receivers understand and interpret the message correctly, and the marketers will achieve their advertising purpose.

The third factor was the congruency between the athlete's endorser and advertised product which had a positive, direct but low-intensity relationship. In Iranian mass media, athletes are less likely to be used in advertising related to their professional sport, such as using them for promotion hot drinks, canned products, dairy, engine oil companies and so on. Therefore corporate advertising and marketing managers should consider the congruency between endorser and advertised product. It means, if they want to select an athlete to endorse or support their product, it should be a sporting item or sport-related product (Esmaeilpour, Bahrainizadeh, \& Zarei, 2017). This heterogeneity and incongruence between the athlete and promotional product do not have the expected effect on the consumers' attitude. The congruency between the athlete and the promotional product has a direct and positive relationship with the attitude towards the advertisements. When a promoted product and endorser is in a right way, the impact of this congruency is also on the success of the promotional campaign. To succeed in the customer markets, the congruency between the product and the advertiser plays a significant role in the minds of the consumers and encour- ages them to buy the product (Kamins, 1990; Kahle \& Kahle, 2006). A real example of the congruence between the athlete and the promotional product was in the advertise that Nike company has done on his sports shoes using Michael Jordan, NBA basketball player star, where both have gained huge profits from this targeted partnership. Contrary to this issue can be seen in the lack of congruency \& coordination between Tiger Wood and Buick Cars (Smith \& Stewart, 2014). Although Wood is one of the most famous and valuable athletes, his partnership with Buick was not successful. When people were shocked by seeing the image of the Tiger in the advert of the Buick company, they explained that the Tiger Wood image could have been more logical and better aligned with the Cadillac machine (General Motors Manufacturing), rather than Buick, because Cadillac is a symbol of a much more expensive, more luxurious and sporty car that has a more congruence and integrated with the Tiger Wood character (Thomaselli, 2008). The fourth factor in this study was the recommendations and testimonial made by the athlete which had a direct correlation with the moderate-intensity with the dependent variable. This means, by rising the recommendation and guaranteeing the products or services offered by athlete endorser, the positive attitude toward the advertising become increased. Among the four independent variables, the testimonial variable had the strongest effect on the attitude towards advertisement or sports endorsement. The testimonials that make by a celebrity are a great way to encourage audiences to buy a product because they trust them and make the best of their recommendations and promotions. Based on this view, brands usually rely on celebrity reputation to have excellent communication with the target community. Consumers would believe that athletes recommend the products honestly with their professional judgment. Therefore attitude toward advertising and purchase intention could enhance by sports endorsement (Tsai \& Wang, 2019). If athlete testimonial want to be more effective on consumers' attitude, the celebrity should suggest their experience with the product as evidence to support their recommendation and comparing the high quality and durable of endorsed products to other offerings from different brands (Matenga, 2019).

Generally, the results of this study showed that there is a significant relationship between sport's endorsement in social media and consumers' attitude towards advertising. Among the four factors, the recommendations and guarantees (testimonial), provided by athletes can be a good predictor of the consumer attitude towards the advertising promoted by athletes. Besides, people have been pro- 
moted in both the traditional marketing space and the massive social media space. Therefore, it's better to do advertise immensely and effectively so that the consumers eager to see the advertisements, and the endorsement will have the greatest impact on the minds of the audiences and the consumers. However, in Iran, Social media seems to have not yet managed to use its potential position to gain public reliance on the accuracy of its advertising. On the other hand, it is thought that this particular trust and attention of the athletes by the people indicate their special popularity in the community. This trust, confidence, and attention to athletes by people show their special status among the Iranian community. So, with the analysis, one can hope that the sport's celebrities and their popularity will be used to improve the position of advertising on social media and society and will seek to inform and identify the product to customers, as well as easier access, with trust the quality and services of the products.

\section{REFERENCES}

Andrews, J. C., \& Durvasula, S. (1991). Suggestions for manipulating and measuring involvement in advertising message content. Advances in Consumer Research, 18(1). doi:https://doi.org/10.1080/00913367.1990.10673198

Campbell, C., Pitt, L. F., Parent, M., \& Berthon, P. R. (2011). Understanding consumer conversations around ads in a web 2.0 world. Journal of Advertising, 40(1), 87-102. doi:https://doi.org/10.2753/joa0091-3367400106

Chiu, W.-S., Wen, Y.-C., \& Lin, K.-W. (2019). The influence of the NBA star endorsers' crediblity and brand image on purchase intention: A case study of Taiwanese american player jeremy lin. European Journal of Management and Marketing Studies, 4(2), 20-33.

Cunningham, N. (2012). Nothing but net: Measuring the effectiveness of athlete endorsements in social media (Unpublished doctoral dissertation). Texas Christian University, Fort Worth, Texas.

Cunningham, N., \& Bright, L. F. (2012). The tweet is in your court: Measuring attitude towards athlete endorsements in social media. International Journal of Integrated Marketing Communications, 4(2), 73-87.

Darmawan, D., Mardikaningsih, R., \& Hariani, M. (2019). The effects of endorser credibility, attitude toward to ADS, and brand attitude on purchase intention. Relasi: Journal Ekonomi, 15(2), 263-276. doi:https://doi.org/10.31967/relasi .v15i2.311

Elberse, A., \& Verleun, J. (2012). The economic value of celebrity endorsements. Journal of Advertising Research, 52(2), 149-165. doi:https://doi.org/10.2501/jar-52-2-149-165

Esmaeilpour, M., Bahrainizadeh, M., \& Zarei, K. (2017). Investigating the effect of celebrity endorsements in advertising on consumer attitudes toward advertising. The Journal of Modern Marketing Researches, 24(1), 1-22.

Feick, L., \& Higie, R. A. (1992). The effects of preference heterogeneity and source characteristics on ad processing and judgements about endorsers. Journal of Advertising, 21(2), 9-24. doi:https://doi.org/10.1080/00913367.1992.10673364

Jatto, 0. (2014). Consumer attitude towards celebrity endorsements on social media (Unpublished doctoral dissertation). Dublin Business School, Dublin, Ireland.

Kahle, K. E., \& Kahle, L. R. (2006). Sports celebrities' image: A critical evaluation of the utility of Q scores. In, Creating images and the psychology of marketing communication. London, UK: Psychology Press.

Kamins, M. A. (1990). An investigation into the "match-up" hypothesis in celebrity advertising: When beauty may be only skin deep. Journal of Advertising, 19(1), 4-13. doi:https://doi.org/10.1080/00913367.1990.10673175

Koo, G.-Y., Ruihley, B. J., \& Dittmore, S. W. (2012). Impact of perceived on-field performance on sport celebrity source credibility. Sport Marketing Quarterly, 21(3), 147-155.

Laurell, C., \& Söderman, S. (2018). Sports, storytelling and social media: A review and conceptualization. International Journal of Sports Marketing and Sponsorship, 19(3), 338-349. doi:https://doi.org/10.1108/ijsms-11-2016-0084

Leng, H. K., \& Chiu, W. (2019). The 27th SEA games Myanmar 2013: A facebook perspective. Sport in Society, 22(3), 449-461. doi:https://doi.org/10.1080/17430437.2018.1490270

Manta, A. (2013). The celebrity athlete: A powerful endorsement tool in the mass media. Boston, MA: Boston Press.

Martin, J. H. (1996). Is the athlete's sport important when picking an athlete to endorse a nonsport product? Journal of Consumer Marketing, 13(6), 28-43. doi:https://doi.org/10.1108/07363769610152581

Matenga, C. T. (2019). The rise of virtual athletes: The influence of uses \& gratification and para-social interaction on consumers' attitudes towards high-involvement products endorsed by micro-celebrities (Unpublished doctoral dissertation). The University of Waikato, Hamilton, New Zealand. 
Mudrick, M., Sauder, M. H., \& Davies, M. (2019). When athletes don't" stick to sports": The relationship between athlete political activism and sport consumer behavior. Journal of Sport Behavior, 42(2), 45-60.

Mullin, B. J., Hardy, S., \& Sutton, W. (2014). Sport marketing. London, UK: Human Kinetics.

Ohanian, R. (1990). Construction and validation of a scale to measure celebrity endorsers' perceived expertise, trustworthiness, and attractiveness. Journal of Advertising, 19(3), 39-52. doi:https://doi.org/10.1080/00913367.1990 .10673191

Polat, F., Subay, O. O., \& Uluturk, A. S. (2018). Hate speech in turkish media: The example of Charlie Hebdo attack's. Journal of Advanced Research in Social Sciences and Humanities, 3(2), 68-75. doi:https://doi.org/10.26500/jarssh-03-2018 $-0204$

Pranee, S., \& Papapankaid, C. (2017). Factors affecting purchasing decision of community products in Ranong province. International Journal of Business and Administrative Studies, 3(2), 79-83. doi:https://doi.org/10.20469/ijbas.3.10005 $-2$

Putra, P. Y., \& Ningrum, S. (2019). The influence of celebrity endorser, brand image, and brand trust on consumer purchasing decisions of nike brand sport shoes in Surabaya. In Proceeding of World Conference, California, CA.

Saputra, R., \& Dewi, C. K. (2016). The impact of brand trust on brand loyalty mediated by customer satisfaction: Case of Tokobagus.com (now OLX.co.id). Journal of Administrative and Business Studies, 1(1), 8-13. doi:https://doi.org/ 10.20474/jabs-1.1.2

Schaefer, A. D., Parker, R. S., \& Kent, J. L. (2010). A comparison of American and chinese consumers' attitudes toward athlete celebrity endorsers. Journal of Applied Sport Management, 2(1).

Smith, A. C., \& Stewart, B. (2014). Introduction to sport marketing. London, UK: Routledge.

Stever, G. S., \& Lawson, K. (2013). Twitter as a way for celebrities to communicate with fans: Implications for the study of parasocial interaction. North American Journal of Psychology, 15(2), 339-354.

Sudarmiatin. (2019). Place branding: An alternative model for empowering Small and Medium Enterprises (SMEs). International Journal of Business and Economic Affairs, 4(2), 77-84. doi:https://doi.org/10.24088/ijbea-2019-42003

Swinyard, W. R. (1993). The effects of mood, involvement, and quality of store experience on shopping intentions. Journal of Consumer Research, 20(2), 271-280. doi:https://doi.org/10.1086/209348

Thomaselli, R. (2008). With no ring, james is still no Jordan; behind the continuing quest to turn the NBA's biggest endorser into a global icon.(news). Advertising Age, 79(4), 47-59.

Till, B. D., \& Busler, M. (2000). The match-up hypothesis: Physical attractiveness, expertise, and the role of fit on brand attitude, purchase intent and brand beliefs. Journal of Advertising, 29(3), 1-13. doi:https://doi.org/10.1080/ 00913367.2000 .10673613

Tsai, C.-S. W. L.-F., \& Wang, P.-W. (2019). The relationships between sports star endorsements and advertising effects. Web Journal of Chinese Management Review, 15(4), 1-25. doi:https://doi.org/10.1016/j.jdmm.2019.100367

Whiting, A., \& Williams, D. (2013). Why people use social media: a uses and gratifications approach. Qualitative Market Research: An International Journal, 16(4), 362-369. doi:https://doi.org/10.1108/qmr-06-2013-0041

Williamson, D. A. (2011). Social network ad revenues rising worldwide. Retrieved from https://bit. Iy/3cFNRKY 